\title{
La batalla de Chile: imagen, poesía, memoria
}

\author{
La nostalgia de la luz | Patricio Guzmán | 2010
}

\section{Derek Humphreys*}

Université Paris 13

Recepción: 15 de diciembre de 2019; aceptación: 2 de febrero de 2020

\begin{abstract}
Resumen
El trauma, por definición, no se inscribe psíquicamente. Por esta razón, la violencia de estado solo deja huellas sin forma que son del orden de lo discontinuo, de lo fragmentado. Frente a esta experiencia, la construcción de una imagen-movimiento como fundamento de un relato permite integrar la experiencia, incluyendo la del trauma, y despliega así una novela individual, una memoria e incluso mitos colectivos de elaboración del horror. Ahora bien, no es solamente una simple referencia a la imagen que permite este relato, sino que es una imagen fantasmática, desfasada de toda organización común y que organiza el relato por la "figuración" que despliega en torno a un vacío enigmático. Es a partir de las películas en las que el artista sudafricano William Kentridge interroga la función del "memorial” en lugares que conocieron la violencia del apartheid -a veces, olvidada- que propongo una mirada sobre la mutación de los registros del documentalista Patricio Guzman, entre la pura inscripción de la imagen en "La batalla de Chile", hasta el montaje poético de "Nostalgia de la luz". En este análisis, acerco esta función poética al concepto del fantasma en Freud para pensar luego la noción de creatividad como posibilidad de acceder a la vida a partir de las huellas amorfas originarias de D.W.Winnicott.
\end{abstract}

Palabras clave: Trauma | Golpe de estado | Memoria | Imagen | Juego

The battle of Chile: image, poetry, memory

\begin{abstract}
The trauma, by definition, leaves no traces in the psychic apparatus. This absence becomes even more complex when the trauma is linked to state violence, which leaves only shapeless, discontinuous and fragmented traces. When we are confronted with this type of experience, the construction of a movement-image as the basis of a narrative allows us to integrate these experiences, even that of the trauma, by deploying an individual novel, a memory and a collective myth of horror. However, it is not the simple reference to the image that this access to a narrative makes possible, but rather a fantastic-fictionnal one, shifted from any " ordinary sense " and which the narrative organizes by the "figuration" which it deploys around an enigmatic void. It is from the films in which the South African artist William Kentridge questions the function of the "memorial" in sites, sometimes forgotten, having witnessed the violence of apartheid, that I propose an approach to the mutation of registers that can be seen in the work of the documentary filmmaker Patricio Guzman, between the pure inscription of the image in "La batalla de Chile", up to the poetic montage of "Nostalgia de la luz". In this analysis, I propose a parallel between the poetic function of the movement-image and the question of fantasy in Freud, to then think about the notion of creativity, defined as the possibility of accessing life from primary shapeless traces by DW Winnicott.
\end{abstract}

Keywords: Trauma | Coup | Memory | Image | Play

\section{Introducción}

La persecución política, la violencia de estado y la tortura pertenecen al registro de lo que habitualmente llamamos traumático. El trauma es, por definición, lo que no deja huellas en el aparato psíquico, lo que no se inscribe y que, en tanto tal, permanece inaccesible a la psicoterapia -que, por su parte, puede intervenir únicamente sobre hechos y material psíquico. El evento que nos interesa aquí es por lo tanto vivido y revivido cada vez con la misma intensidad, a un nivel puramente sensorial, en la disconti- nuidad y la desorganización que caracterizan la experiencia corporal toda vez que esta no encuentra un relevo en la imagen y en la organización de una narración capaz de establecer sentido y continuidad a lo vivido.

A pesar de haber trabajado en torno a lo no-inscrito psíquicamente durante varios años -especialmente los procesos de exclusión que se manifiestan en la errancia y la gran precariedad, pero también en el análisis con bebés y la clínica de lo informe- había querido evitar, hasta hace muy poco, toda reflexión teórica que pudiese referirse a los efectos traumáticos del golpe de estado y de la violencia de

* derek.humphreys@gmail.com 
la persecución política y la tortura en Chile, tratándose de eventos que me tocan de manera demasiado directa y respecto de los cuales no podía mantener la objetividad necesaria a la elaboración teórica. Había podido, sin embargo, abordar el problema de la elaboración de este tipo de trazas traumáticas de manera tangencial durante los últimos 6 años en una reflexión respecto de la guerra de Argelia y los efectos psíquicos asociados a la ausencia de reconocimiento oficial en Francia de estos hechos. Esta reflexión me había permitido afirmar la importancia de un trabajo de memoria y de reparación de estos acontecimientos (Humphreys, 2018). Podría decirse que mi interés por las huellas dejadas por la guerra de Argelia había sido efecto del azar: aunque era sabido en Chile que la muchas de las técnicas de desinformación, de persecución y de tortura utilizadas por el régimen de Pinochet eran el producto de la transmisión de una estrategia militar instalada un poco antes en Argelia ${ }^{1}$ esta transmisión no es discutida frecuentemente en Francia. Por otra parte, cuando tuve la posibilidad de discutir con mis estudiantes en Francia algunas situaciones clínicas dramáticas asociadas a la dictadura chilena, este aspecto traumático del evento violento era escuchado con una cierta distancia y como algo totalmente impensable en Francia, en circunstancias que en muchos análisis en Francia me encontraba con las trazas dolorosas, angustiosas e informes dejadas por la guerra de Argelia. La ausencia de un trabajo de inscripción y de memoria, que asociaba en mis hipótesis a la falta de reconocimiento cultural, nacional, me parecía inquietante. Este trabajo me había así permitido afirmar que solamente después de una primera organización respecto del entorno cultural y social es posible dar un sentido a la experiencia traumática. Para que esta organización sea posible, es necesaria la inscripción de ciertos hechos concretos en la Historia de un pueblo, de una nación. Es solamente después de esta primera inscripción que estas trazas pueden hacer parte de una biografía, inscribirse en la historia de una familia y tener, finalmente, un efecto simbólico de transmisión. Esta proposición proponía una continuidad con el trabajo efectuado por Daniel Mendelsohn sobre el trauma del holocausto y su posible inscripción individual en su libro "Los hundidos" (2006).

\section{Cine y sueño}

Esta reflexión se organizó definitivamente en un artículo que se basaba en la propuesta estética de otro extranjero al problema francés, que había también co- nocido los efectos de un régimen totalitario: Michael Haneke, en su película sobre la guerra de Argelia de 2005, Caché (Escondido). En este análisis, me interrogaba sobre el efecto de incomprensión con el que había sido recibida en Francia esta película y sobre la ausencia casi total de consecuencias de esta proposición de una elaboración común en términos de reconocimiento de un trauma compartido, como pueden hacerlo a veces las películas. Explicaba esta incomprensión como un efecto de la ausencia de inscripción en la cultura de los eventos traumáticos asociados a la guerra de Argelia. A partir de esta ausencia de elaboración común, compartida culturalmente, todo el resto resulta imposible.

En mi análisis de la película de Haneke, me interesaba especialmente lo que aparece como una ausencia, un agujero, un vacío. Este último es especialmente sensible en una visita del protagonista a su madre, que tiene como finalidad la elucidación del nudo del relato, y el origen del sentimiento de culpabilidad que persigue al protagonista. Sin embargo, aunque al final de una larga escena en la que nada es dicho entre estos dos personajes, a la excepción de un cierto número de fórmulas superficiales, es anunciado un desayuno entre los dos, en el que la despedida podría crear las condiciones en las que se revela el conflicto... Haneke filma la puerta que se abre, el protagonista que va al encuentro de su madre, y en seguida se produce el corte de la escena. El encuentro se presenta, así como un agujero, un espacio en blanco en el relato.

A través de esta escena vacía, que subraya la negatividad en torno a la que se organiza el conflicto del protagonista, me parecía posible el establecimiento de una correlación entre cierto tipo de presentación fílmica y la noción de imagen icónica que Freud (1901) propone en La interpretación de los sueños. Este tipo de tratamiento icónico, que es necesario diferenciar de la simple imagen (que no es la que interesa a Freud en el sueño, ni en el fantasma), se apoyaba en algunas secuencias cinematográficas, de Raúl Ruiz y de David Lynch. El interés de esta dimensión icónica, en oposición a la imagen-movimiento que permite establecer la continuidad del relato, reside en su capacidad de contener elementos afectivos enigmáticos a partir de los cuales es posible llevar una experiencia traumática al terreno psíquico, haciendo así la experiencia traumática accesible a través de la palabra y por esto mismo, elaborable.

En efecto, Freud (1986) había comprendido la importancia del trauma en sus primeras reflexiones sobre la histeria, y proponía que la única manera de acceder a estas escenas es a través de la fantasmatización. Aunque 
rápidamente se aleja de toda búsqueda de un evento real traumático, Freud no abandona su interés por el elemento enigmático que federa la construcción del fantasma -o motivo secreto, como lo llama en el artículo en el que se construye la noción de fantasma, el recuerdo de infancia de Leonardo da Vinci ${ }^{2}$. Este núcleo enigmático es característico del trauma, permitiéndonos definirlo más por su intensidad y por su capacidad de hacer efracción en el aparato psíquico que por el "evento" que hace trauma. A pesar de esta "anhistoricidad" del trauma, resulta imposible, en algunos casos, disociar la experiencia traumática del hecho histórico. Este aspecto me parece especialmente importante cuando se trata de eventos que la historia o la cultura ocultan, niegan, borran, impidiendo su elaboración. Este tipo de hechos se manifiestan sintomáticamente de manera informe -en Caché a través de una culpabilidad difusa e informe, extremadamente violenta- muchas veces en una transmisión intergeneracional difícil de situar, de reconocer y de tratar-aspecto también extensamente tratado en Caché.

\section{Trauma y creación}

Winnicott propone, en Realidad y Juego (1971), que la creatividad que interesa al psicoanálisis no es la del artista, sino aquella que nos permite vivir, o seguir viviendo a pesar, a veces, de haber vivido situaciones extremas. Winnicott, citando a M. Milner, refiere esta creatividad a la del poeta originario o "primitivo". Este es descrito así justamente porque los momentos en los que él crea el mundo exterior “....al encontrar lo familiar en lo desconocido, son quizás olvidados por la mayoría de las personas, o bien se los guarda en algún lugar secreto del recuerdo, porque se parecen demasiado a visitas de los dioses como para mezclarlos al pensamiento cotidiano..." (Milner, 1957 en Winnicott, 1971, p. 62). Es interesante notar que esta creación de lo familiar a partir de lo no-familiar es la manera en la que Winnicott nos introduce a la relación entre juego y masturbación, como una experiencia corporal informe y discontinua, que pertenece a un registro extra-psíquico, pero que en la repetición es reconocida e incluida por el sistema simbólico, de lenguaje, por el que accede a la continuidad de la representación y de lo imaginario. Así, los confines del sujeto, que son referidos aquí a lo primitivo u originario, y que Kristeva (1980) describe como lo interno-horroroso que necesita ser olvidado en la construcción de la continuidad habitual del Yo, nos permiten pensar el es- tatuto de lo que Freud llama Unheimliche y que debe ser asociado al romanticismo de Jena.

El rol del juego consiste en la estabilización de una experiencia corporal (en su descripción inaugural, se trata del gesto con el que el nieto de Freud, Ernst Halberstadt, lanza un carretel produciendo un sonido para luego recuperarlo con una vocalización diferente) a través de la posibilidad de encontrar en esta experiencia un substituto a la ausencia (de la madre en este caso) (Freud, 1920). Lo que llamamos aquí experiencia corporal, que incluye tanto el gesto del brazo como la producción de un sonido, toma un valor simbólico en el reconocimiento de una vocalización (que asocia el gesto al ruido producido simultáneamente) interpretada por Freud cuando los asocia a un sentido, que entonces nombra (Fort y Da). Así, la exposición a una intensidad de afecto que el niño no puede controlar y que no constituye más que una fuente de inestabilidad, se transforma en un juego se substituciones metafóricas en las que la palabra intercambia su lugar con la cosa ausente. Aunque nuestros intercambios con otros y las formas en las que nos representamos a nosotros mismos se desarrollan casi únicamente dentro de este registro simbólico, es el poeta primitivo, ocultado por el horror de lo ominoso/ Unheimliche, el que ha jugado con la vocalización y la experiencia antes de llegar a la organización de la significación y del sentido. Este poeta originario es el que abre la aventura de Fausto, con una fonación, un ¡ARGH! que se transforma en sentido en lo que Goëthe trata de capturar y que Freud remite sin cesar al acto poético ${ }^{3}$.

Si el ruido producido por Fausto se transforma en creación (del dinero, de la política, de la literatura, del amor, de la guerra), en relato, en historia, podemos suponer que el poeta crea la continuidad de la imagen (del Yo en tanto objeto, de las representaciones sociales) a partir de la discontinuidad de la experiencia original, primitiva, de un gesto corporal aún sin inscripción simbólica ni sentido. El sentido puede ser entendido solamente en el contexto de la secundarización, del proceso por el cual lo informe se organiza para dar origen a un relato capaz de establecer la continuidad que crea el Yo a partir de una serie de instantes corporales disociados. El romanticismo alemán nace de esta pregunta sobre la continuidad, sobre la relación entre lo humano y lo natural, sobre aquello que permanece siempre inaccesible, lógicamente incomprensible. Es ésta probablemente la razón por la que Freud no deja de evocar la importancia del poeta en el acceso a los contenidos inconscientes, a aquellos deseos que permanecen inaccesibles y que no dejan de sorprendernos. La presencia del poeta perdura y reapa- 
rece sin cesar en Ferenczi, Bion, Fédida, Lacan... probablemente porque se trata de una manera de indicar la importancia de la textura, del espesor, de la tonalidad y la intensidad del discurso, y la imposibilidad de organizar estos aspectos de manera objetiva o de reconocernos en el contenido y la linealidad de un relato. Si Freud (1919) evoca los acertijos de las brujas de Macbeth en Pegan a un niño como los únicos capaces de darle sentido al enigma de la experiencia vivida, es probablemente para situar el estatuto significante de los elementos brutos, rudimentarios de la experiencia, de lo real. En esta calidad textual y rudimentaria reposa toda la función creativa.

Es en este contexto que podemos entender el rol del poeta primitivo al que se refiere Winnicott (1971) como creador de un relato a partir de una serie de elementos inconexos, rudimentarios, discontinuos, heteróclitos. La relación establecida con la masturbación se refiere al paso necesario por una experiencia corporal, de sensación y motilidad en la inscripción de estos elementos inicialmente informes. El cuerpo propio aporta así los elementos de figuración y repetición que dan acceso a la apropiación de la experiencia. Luego, el juego de substituciones en torno a la repetición en el cuerpo permite la organización de una continuidad y, finalmente, un relato (y una identificación a este relato, un Yo). Las situaciones clínicas abordadas por Winnicott (1971) en esta reflexión nos permiten pensar que los elementos informes que interesan al poeta primitivo que el analista encuentra de vez en cuando en su trabajo no se limitan a la infancia, sino que pueden permitirnos trabajar con las trazas informes de lo traumático, de todo aquello que no ha podido inscribirse psíquicamente. Si la única posibilidad para un analista de traer al espacio de la sesión lo traumático es accediendo a una forma de inscripción del trauma, la situación de contingencia que representa el juego constituye una forma de trabajar con estos contenidos informes. El juego se introduce así en el espacio de la sesión como un paradigma de actualización, en el cuerpo y de manera repetitiva y controlable, de lo informe-traumático.

Podemos suponer entonces que la aproximación al trauma, en psicoanálisis, exige un trabajo respecto de lo actual antes de intentar una búsqueda histórica. La construcción de un relato sería una anticipación inadecuada que no permitiría reactualizar de manera útil los elementos todavía informes del trauma. El analista, en este tipo de situaciones, requiere un cierto tiempo de reconocimiento, a un nivel puramente transferencial, de los bordes de la cicatriz caótica y puramente sensorial asociada a la experiencia traumática. Estos bordes se manifiestan en el surgimiento de defensas arcaicas, detenciones abruptas en el relato y en la memoria. Este reconocimiento requiere, por lo demás, una contextualización y una traducción por parte del analista. Es a este respecto que podemos afirmar que el punto de partida de trabajo se apoya sobre el lugar político y social que ocupa el psicoanálisis, no como una elección política o social, sino como un reconocimiento de la dimensión política y social en la que se inscribe la historia subjetiva.

Nos referíamos hace un momento a lo que federa de manera informe la construcción del fantasma. Es en este punto que toma sentido la particularidad de esta noción respecto de lo traumático. Recordemos al respecto que Freud (1901) siempre se refirió a la fantasía en su capacidad de generar imágenes, y que la noción de fantasma es introducida por los traductores franceses de la palabra fantasie en un intento de apertura hacia los otros sentidos en los que se escucha en su lengua original ${ }^{4}, y$ que tienen que ver con una imagen icónica compleja que no puede ser limitada al puro registro imaginario en el que la escuchamos habitualmente. Se trata, en efecto, de imágenes icónicas que deben ser leídas como jeroglíficos y que corresponde a aquellas que encontramos en el sueño, en la escena primordial o en el recuerdo encubridor. Este tipo de imagen es la materia prima con la que trabajan el artista y el poeta y es el elemento constitutivo de lo que Winnicott (1971) llama jugar. En efecto, en el contexto del análisis, se trata de la posibilidad de apoyarse sobre las figuras evocadas en la sesión o incluso en los elementos disponibles en la pieza, como efecto de un encuentro contingente en torno a una experiencia afectiva, un poco como el juego del "cadáver exquisito", en el que se construye en lo inmediato de los intercambios una forma nueva a partir de pedazos aportados por cada participante.

\section{Cartografía y memoria}

El artista visual William Kentridge propone un trabajo sobre lo informe, el origen de las imágenes y nuestra apropiación individual del objeto a partir de una imagen en dos dimensiones, a partir de la cual ha podido introducir una reflexión histórica en Sud-Africa. Kentridge abre esta problematización, entre fantasma, imagen icónica e historia, a partir del aguafuerte en el que Durero representa un curioso rinoceronte en 1515: el pintor, respondiendo a un encargo, creó aquí una imagen fantástica, de un animal que nunca vio, apoyándose en el relato 
de aquellos que sí pudieron verlo. Interrogando la función de médium del papel, en dos dimensiones, Kentridge reflexiona sobre la manera en la que el mundo exterior crea un nuevo registro cuando encuentra, en la hoja de papel o en la tela, el mundo representacional del artista, su propio mundo interno. El papel deviene así pantalla, superficie de proyección para una imagen compuesta de elementos dispersos y heterogéneos, que existen en el mundo real solamente de manera desorganizada, discontinua y caótica, sin ninguna relación temporal o de causalidad. Estos elementos organizan sin embargo una figura que aporta algo de la realidad, en este nuevo registro; ante la muerte del rinoceronte, Durero debe contentarse de los rasgos que quedan en el recuerdo de quienes lo vieron para producir una imagen fantástica, que tiene algo del rinoceronte pero que no es el rinoceronte sino una creación contingente, de un momento, producto de una serie de encuentros aleatorios: la imagen es una reconstrucción, o mejor aún, una construcción en la que hoy podemos reconocer un rinoceronte, probablemente dotado de una especie de armadura, con cuernos y pelos que hacen de esta representación una composición mítica que no podemos sino llamar el rinoceronte de Durero. ¿Hasta qué punto se trata de un rinoceronte, y donde comienza a ser otra cosa, una composición, un animal mítico, un fantasma de Durero?

El trabajo de Kentridge (1974) consiste aquí en la creación de una continuidad narrativa, comprensiva, a partir de los elementos discontinuos del mundo exterior, la necesidad de crear una imagen como ideal (en este caso del renacimiento, y probablemente también para Durero) efecto de una composición abstracta con una cierta relación a la realidad. La idea misma de la composición a partir de un fragmento informe, de una mancha capaz de evocar una imagen y un relato, se desarrolla en Kentridge sin jamás abandonar la importancia de los espacios blancos o los vacíos que persisten y crean un enigma que nos obliga siempre a ajustar la percepción a partir de una composición. Estos vacíos enigmáticos constituyen así un eje organizador, un vector narrativo de la imagen.

Es justamente en torno a estos blancos que Kentridge (1974) piensa el lugar de la historia y la política en Sud-África: la desaparición, la muerte, el apartheid. Así por ejemplo en Felix in exile (1994) nos propone una reflexión sobre aquellos que murieron o fueron abandonados a la muerte durante las manifestaciones populares a través de una serie de recortes y dibujos hechos sobre un periódico y destinados al olvido. Kentridge cuestiona así el valor de la traza gráfica, de la fotografía e incluso del memorial. Concretamente, interroga el valor de la placa instalada en recuerdo de algo, asociando un número a un lugar, cuando dicho lugar se transforma en atracción turística. La placa, en estas condiciones, traiciona la memoria, ocultando los hechos detrás del nombre, la cifra asociada (de muertos, de desaparecidos...) y el evento devenido espectacular y turístico; se trata de la placa del espectáculo televisivo en el que se indica al público cuando reír y cuando aplaudir. En este desplazamiento del deber de memoria a una placa que nos recuerda lo que sucedió en un lugar dado, no logramos ya mantener presente de manera vívida, realmente inscrita en el paisaje mismo, la traza de los hechos que es necesario marcar, reconocer, recordar. Aceptando que se trata de una tarea imposible, Kentridge nos invita a reflexionar así sobre la paradoja de un recuerdo auténtico cuando este es reducido a unas cuantas indicaciones inscritas sobre una placa con el propósito de recordarnos de manera simple la dificultad que encontramos para efectuar un trabajo permanente de memoria. Kentridge desarrolla en este ejercicio un sistema de marcación capaz de surcar el paisaje, deteniéndose en lugares en los que ninguna huella nos permite reconocer que se trata de lugares en los que los manifestantes fueron matados y enterrados. Estas desapariciones sin huellas exponen la imposibilidad de dar origen a una imagen sobre la que se apoye el relato de lo sucedido... incluso una imagen construida, de algo que nunca existió, permite que la verdad siga siendo dicha.

En Felix in exile (1994), Kentridge hace así de los desaparecidos, de los manifestantes caídos, una traza viva inscrita en el suelo, integrada al paisaje en un trabajo que podríamos calificar de anti-metafórico en la medida en que su intención no es crear substituciones, o inventar imágenes simbólicas, sino profundizar sobre la metáfora misma en el ejercicio de surcar y excavar el paisaje. Es este ejercicio lo que hace traza y memoria, que resiste a la desaparición, al borramiento y al olvido.

Este trabajo de memoria nos permite pensar el rol de lo informe en la "construcción" de una huella capaz de constituir el soporte a una narratividad, a la escritura de la historia, en lo que Winnicott (1971) refiere al poeta originario: un real discontinuo y desorganizado, que pertenece al registro de lo fantasmático y que es, en tanto tal, incapaz de hacer memoria, juega con los restos de lo real, con las personas presentes y con la contingencia de manera creativa, abriendo nuevos sentidos en los intercambios actuales que producen estos restos de real. Winnicott (1971) pone evidentemente el acento en el juego, entendido no tanto como la capacidad de ordenar los 
restos caóticos de lo real sino en su relación a la creación contingente, el acto poético que le da sentido a la vida.

\section{Del documental a la creación poética, el trabajo de memoria de Patricio Guzmán}

Patricio Guzmán se hizo mundialmente conocido por su trabajo documental en torno al movimiento político y social que llevó a la elección en Chile de Salvador Allende y al golpe de estado con el que se dio inicio a la dictadura de Pinochet. La importancia de la trilogía de Guzmán es innegable, no solamente por el reconocimiento internacional que tuvo en tanto documental político (premiado en Paris, Leipzig, Bruselas y La Habana) sino por el rol que tiene hasta hoy en la construcción de una memoria de los hechos ocurridos en Chile entre la organización de un poder popular que culminó con la elección de Allende en marzo de 1973, y el golpe de estado del 11 de septiembre del mismo año. Todos los trabajos y documentos que se refieren a este periodo de la historia de Chile citan a Guzmán y muchas de las imágenes del documental permanecen presentes en los chilenos, como las imágenes (icónicas) en torno a las que se organiza una serie de recuerdos traumáticos.

A pesar del importante trabajo de recopilación y de archivo que constituye esta trilogía de más de 3 horas y media de duración, me parece que este documento visual no ha favorecido la organización de un relato subjetivo, la apropiación individual de los hechos violentos vividos en Chile en torno al golpe de estado y la instalación de la dictadura. En efecto, estas imágenes parecen organizar algunos elementos de la realidad en torno a momentos o recuerdos precisos, pero la experiencia traumática individual, que se actualiza a través de fragmentos sensoriales desorganizados de la vivencia dolorosa, permanecen en un estado caótico que no abre, de manera general, hacia una vía nueva de incorporación, de comprensión, de inclusión en una secuencia ordenada e inscrita en la historia oficial.

Podemos constatar el cambio que se ha operado en el trabajo de Guzmán durante estos últimos años, un pasaje desde la voluntad de escritura documental, asociada a la búsqueda de una verdad material y de una relación de causalidad entre varios hechos, y que podríamos asimilar al trabajo de anamnesis y de estudio de caso que efectuamos en la clínica, a un trabajo más bien poético, de valor subjetivo e individual, en los últimos años. Esta transformación me parece especialmente evidente a par- tir de Nostalgia de la luz, de 2010, y parece instalarse de manera estable en las producciones recientes.

En Nostalgia de la luz, Guzmán articula una serie de relatos completamente heterogéneos de personas que en el mismo lugar (el desierto de Atacama) pero en registros diferentes, hablan de una exploración del entorno espacial y temporal. Así, un astrónomo habla de la exploración de los movimientos estelares en el tiempo mientras un arquitecto piensa cómo se organizaba la vida en los campos de concentración de detenidos políticos a partir de las huellas dejadas por sus antiguos ocupantes, y algunas mujeres solas exploran la dura y árida tierra desértica con un pincel y una pala con la esperanza de encontrar algún resto capaz de dar algún indicio para la búsqueda de un hijo o de un marido desaparecido durante la dictadura de Pinochet. El entrecruzamiento de estos relatos individuales y subjetivos, cada uno en su jerga específica y sin embargo con un motivo común, se hace metáfora de la muerte, de la vida, de la pérdida, y de la búsqueda de sentido. En esta creación poética, Guzmán no aporta los elementos para una prueba de realidad ni trata de explicar las causas o los efectos de algunos hechos históricos, sino que los presenta en su materialidad para que cada uno pueda ponerlo a trabajar en la organización subjetiva de lo traumático. Como en el trabajo de Kentridge, se trata de surcar, cartografiar una parte del paisaje, un territorio marcado por hechos históricos violentos que han tratado de ser olvidados, en búsqueda de una manera de actualizarlos no en las cifras, que son siempre generales y sintéticas, sino en la memoria viva que constituye la continuidad entre el paisaje y el hecho histórico con la vivencia individual, el gesto de unos cuantos. En lugar de la exigencia moral, el deber ético de varios movimientos de búsqueda individual converge, resultando en una memoria y en un sentido colectivos.

\section{Conclusión}

Winnicott (1971) se refiere a la posibilidad de dar origen a un sentido a partir de una inscripción capaz de surcar y significar poéticamente las huellas informes y hasta ominosas de lo arcaico. Cuando estos elementos informes asociados a lo traumático, que aparecen siempre de manera inesperada y angustiosa, son utilizados como materia prima para el juego, la actualización en la que se hace posible la convergencia de nuevos afectos, nuevas representaciones y nuevos sentidos, opera una transformación creadora de metáforas que inscribe en 
un nuevo registro las huellas traumáticas. En esta inscripción, estas huellas se hacen accesibles psíquicamente. En este caso, lo que nos ha interesado es la posibilidad de pensar el efecto creador que tienen algunas imágenes respecto del juego, en su capacidad de inscribir la experiencia traumática en un aquí y ahora, por ejemplo en el tratamiento poético de las imágenes que propone Guzmán en Nostalgia de la luz, y que parecen oponerse al valor de enclave que constituyen las imágenes del documental, que instalan puntos de referencia aislados en torno a los cuales siguen gravitando una serie de huellas traumáticas arcaicas e inquietantes que no permiten avanzar en la elaboración del trauma. En el trabajo reciente de Guzmán, la presentación ordenada y lógica de algunos elementos objetivos de la historia es reemplazada por el juego de superposiciones de varios relatos diferentes que se abren hacia un nuevo aspecto, una nueva dimensión posible. Esta dimensión poética es así la que establece las condiciones de repetición que dan lugar a nuevos cruces de sentido, nuevos encuentros en la actualidad, y una re-significación de lo que ha sido instalado de manera dolorosa y traumática, un cuerpo extraño al interior del sujeto. Así, el proceso de maduración y de transformación de la obra cinematográfica de Guzmán, entre verdad histórica y verdad mítica, nos parece en relación con el tiempo de maduración de lo traumático.

\section{Referencias}

Freud, S. Cartas a Wilhelm Fliess (1887-1904). Buenos Aires, Amorrortu, 1986.

Freud, S. (1901). L'interprétation du rêve[La interpretación de los sueños] (J-P Lefebvre traductor). Paris, Seuil, 2010.

Freud, S. (1910). “Un recuerdo infantil de Leonardo de Vinci”. En: Obras Completas, Madrid, Biblioteca Nueva, cuarta edición, 1981.

Freud, S. (1919). “Pegan a un niño”. Contribución al conocimiento de la génesis de las perversiones sexuales. En Obras Completas. Madrid: Biblioteca Nueva, cuarta edición, 1981.

Freud, S. (1920). “Más allá del principio del placer”. En: Obras Completas, tomo 18 (1920-1922). Buenos Aires, Amorrortu, 1976.

Heiduschka, V. (productor) y Haneke, M. (director). (2005). Caché [cinta cinematográfica]. Austria, Francia, Alemania e Italia: Artificial Eye; Sony Pictures Classics.

Humphreys, D. (2018). ”Figurabilidad fílmica: el estatuto pictográfico del cine”. Ética y cine, vol. 8 (2), Buenos Aires.

Kentridge, W. (1994). Six drawing lessons. Harvard, University Press.

Kentridge, W. (productor y director). (1994). Felix in Exile [cinta cinematográfica]. Sudáfrica.

Kristeva, J. (1980). Pouvoirs de l'horreur. Essai sur l'abjection. Paris: Seuil.

Mendelsohn, D. (2006). The Lost : A Search for Six of Six Million. New-York: Harper Collins Libri.

Milkaeloff, H. (curador). Catálogo de la exposición Chili, l'envers du décor/Fondation Louis Vuitton. Paris, Studio Graphique L. Vuitton, 2010.

Sachse, R. (productor) y Guzman, P. (director). (2010). Nostalgia de la luz [cinta cinematográfica]. Chile, Francia, Alemania: Pyramide.

Winnicott (1971). Realidad y Juego. Barcelona, Gedisa, 1993.

1 En «Cara metade» (Chili, l'envers du décor/Fondation Louis Vuitton, Paris, 2010), Mario e Ivan Navarro exponen las técnicas de represión y las políticas de representación colectiva a partir de la formación e información transferida a las juntas militares de América del Sur por parte de divisiones de la inteligencia militar francesa durante los años 70, en especial las técnicas de tortura y represión desarrolladas durante la guerra de Argelia en los años 50.

2 La expresion eines geheimen Motifs, que organiza toda la construccion freudiana del fantasma, se encuentra en una nota al pie de pagina del articulo sobre el recuerdo infantil de Leonardo da Vinci. Cf. Freud, S. (1910). « Un recuerdo infantil de Leonardo de Vinci ». En: Obras Completas, Madrid, Biblioteca Nueva, cuarta edicion, 1981, p.1589.

3 Es necesario precisar aquí la utilización de la palabra Dichtung en Freud. Aunque su traducción literal es la poesía, no puede ser disociada de una dimensión de acto o de actualización de la palabra.

$4 \quad$ Al respecto, ver la nota magistral sobre la cuestión de la traducción y del origen del concepto que desarrolla Jean-Pierre Lefebvre en la introducción à su traducción al francés de Traumdeutung. Cf. L'interprétation du rêve, Paris, Seuil, 2010. 